\title{
FITOSSOCIOLOGIA DO COMPONENTE LENHOSO DE UM REFÚGIO VEGETACIONAL NO MUNICÍPIO DE BUÍQUE, PERNAMBUCO ${ }^{1}$
}

\author{
MARIA JESUS NOGUEIRA RODAL ${ }^{2}$ KARLA VITÓRIA DE ALMEIDA ANDRADE, ${ }^{3}$ \\ MARGARETH FERREIRA SALES ${ }^{2}$ e ANA PAULA SOUSA GOMES ${ }^{4}$ \\ ${ }^{1}$ Trabalho financiado pelo projeto "Composição florística e diversidade dos brejos de altitude de Pernambuco" \\ (Darwin Initiative/CNPq/PNE/UFRPE) \\ ${ }^{2}$ Professora do Departamento de Biologia/UFRPE, Rua Dom Manoel de Medeiros, s/n, \\ CEP 52171-900, Dois Irmãos, Recife, PE \\ ${ }^{3}$ Bolsista CNPq/PNE, herbário Professor Vasconcelos Sobrinho/Departamento de Biologia/UFRPE \\ ${ }^{4}$ Aluna do programa de pós-graduação em Botânica da UFRPE \\ Correspondência para: Maria Jesus Nogueira Rodal, Rua José Moreira Leal, 303, apto. 201, CEP 51030-380, Recife, PE \\ Recebido em 14/05/97 - Aceito em 02/06/98 - Distribuído em 28/08/98
}

(Com 1 figura)

\section{ABSTRACT \\ Phytosociology of the woody component in vegetacional refuge, Buíque, Pernambuco}

Phytosociology of the woody component of a vegetacion refuge in the municipality of Buíque, Pernambuco. Physiognomy and structure of a evergreen shrub vegetation found on the windward slope of the Catimbau range, at the Cigano property, Buíque $\left(8^{\circ} 67^{\prime} \mathrm{LS}\right.$ and $37^{\circ} 1^{\prime} \mathrm{LW}$, altitude $\left.800 \mathrm{~m}\right)$ were determined, as a contribution to the knowledge of the vegetation on sedimentary plateaus of Pernambuco. The point centered quarter method was used with 100 points distributed in 10 parallel lines, each point $10 \mathrm{~m}$ and each line $30 \mathrm{~m}$ apart. All living and standing dead individuals with stem diameter $\oplus 3 \mathrm{~cm}$ at soil level and plant height $\oplus 1 \mathrm{~m}$ were sampled. Total density, total basal area, average and largest diameter and height were 2.208 ind./ha, $6.07 \mathrm{~m}^{2} / \mathrm{ha}, 5.1 \mathrm{~cm}$ and $22.0 \mathrm{~cm}$ and $2.3 \mathrm{~m}$ and $7 \mathrm{~m}$, respectively, revealing a shrub pattern different from those of the caatinga and carrasco studied in Northeastern Brasil. Of the 35 sampled species, Eremanthus capitatus, Piptadenia obliqua, Gochnatia oligocephala, Senna cana var. cana and Eugenia punicifolia were reponsible for $63.3 \%$ of the importance value index total. Shannon diversity index for species was 2.73 nats/ind.

Key words: phytosociology, vegetational refuge, semi-arid.

\section{RESUMO}

Com o objetivo de contribuir para o conhecimento da vegetação lenhosa das chapadas sedimentares do sertão de Pernambuco, foi realizada a caracterização fisionômica e a análise da estrutura da vegetação arbustiva perenifólia localizada em uma vertente a barlavento da serra do Catimbau, na propriedade sítio Cigano, Buíque ( $8^{\circ} 67^{\prime} \mathrm{LS}$ e $\left.37^{\circ} 1^{\prime} \mathrm{LW}\right)$ a $800 \mathrm{~m}$ de altitude. Em cem pontos quadrantes, distribuídos em 10 linhas paralelas, interdistantes $30 \mathrm{~m}$, cada uma com 10 pontos quadrantes distanciados $10 \mathrm{~m}$, foram amostrados todos os indivíduos com diâmetro do caule $\oplus 3 \mathrm{~cm}$ no nível do solo e altura total $\oplus 1 \mathrm{~m}$. Densidade total, área basal total, alturas e diâmetros médios e máximos foram de 2.207,7 ind./ha, $6,07 \mathrm{~m}^{2} / \mathrm{ha}, 2,3 \mathrm{~m}$ e $7,0 \mathrm{~m}, 5,1 \mathrm{~cm}$ e $21,96 \mathrm{~cm}$, respectivamente, revelando um padrão fisionômico distinto das vegetações de caatinga e carrasco estudadas no nordeste do Brasil. Das 35 espécies amostradas, Eremanthus capitatus, Piptadenia obliqua, Gochnatia oligocephala, Senna cana var. cana e Eugenia punicifolia foram responsáveis por 63,3\% do índice do valor de importância total. O índice de diversidade de Shannon para espécies foi de 2,73 nats/ind.

Palavras-chave: fitossociologia, refúgio vegetacional, semi-árido. 


\section{INTRODUÇÃO}

O Nordeste do Brasil apresenta uma área de aproximadamente $1.640 .000 \mathrm{~km}^{2}$ e uma grande heterogeneidade de quadros naturais, que se revelam no clima e vegetação. O clima varia desde o superúmido até o semi-árido, que é limitado pela isoeta de $800 \mathrm{~mm} /$ ano e ocupa uma área de $800.000 \mathrm{~km}^{2}$ (Fernandes, 1996). A caatinga e o carrasco representam os tipos vegetacionais atualmente característicos da região semi-árida, enquanto as manchas de mata úmida, mata estacional, cerrado e cerradão, que ocorrem espalhadas pelo semi-árido, representam vegetações residuais de períodos climáticos mais úmidos (Fernandes, 1996).

Os técnicos do Instituto Brasileiro de Geografia e Estatística consideram que alguns dos tipos vegetacionais brasileiros representam áreas de tensão ecológica e refúgios vegetacionais (IBGE, 1992). Os primeiros ocorrem em locais onde as floras de duas ou mais regiões fitoecológicas distintas se justapõem ou interpenetram, sendo divididas em encraves e ecótonos, enquanto os refúgios se restringem a áreas de pequena dimensão, com vegetação floristicamente diferente do contexto geral da flora da região.

Particularmente nos planaltos e chapadas do semi-árido, ocorrem tipos vegetacionais residuais pouco estudados, como os encraves de mata úmida nos brejos de altitude (Lyra, 1982; Mayo \& Fevereiro, 1982; Ferraz et al., 1998) e a vegetação arbustiva perenifólia das chapadas sedimentares, a qual representa refúgios vegetacionais formados por espécies de caatinga, floresta, campo rupestre e cerrado, dos quais pouco se conhece.

A vegetação arbustiva perenifólia das chapadas do semi-árido distingue-se dos diferentes tipos fisionômicos da caatinga pela completa caducifolia da maior parte dos componentes desta última formação, estratégia utilizada para enfrentar a deficiência hídrica durante a maior parte do ano (Rodal et al., 1992). O atual panorama dos levantamentos fitossociológicos no semi-árido mostra um incremento de trabalhos em áreas de caatinga (Souza, 1983; Santos, 1987; Silva, 1991; Rodal, 1992; Alcoforado-Filho, 1993; Ferraz, 1994; Araújo et al., 1995).

Fernandes (1996) observa que, assim como na caatinga, os indivíduos do carrasco também perdem as folhas. Segundo Araújo et al. (1998), o carrasco distingue-se da caatinga principalmente pela florística, geologia, geomorfologia e hidrologia das áreas onde ocorre. Apresenta fisionomia densa, de 2 a $5 \mathrm{~m}$ de altura, com arbustos e árvores caducifólios, folhas duras, coriáceas e até membranosas. Como trabalhos pioneiros em áreas de carrasco, podem-se destacar o de Araújo et al. (1998) e o de Oliveira et al. (1997), em transição caatinga-carrasco.

Diante da inexistência de levantamentos sobre a vegetação arbustiva perenifólia das chapadas sedimentares, foi realizado o levantamento fitossociológico em uma área da chapada de São José, no município de Buíque, Pernambuco. Nessa chapada ocorrem quatro ambientes com flora e vegetação distintos: a caatinga arbustiva, nas vertentes a sotavento, entre as cotas de 600 a $800 \mathrm{~m}$; o campo rupestre, nas partes mais elevadas, entre 900 e $1.000 \mathrm{~m}$; a vegetação florestal perenifólia, localizada no sopé de algumas serras, na cota de $800 \mathrm{~m}$; e a vegetação arbustiva perenifólia, situada nas vertentes a barlavento, entre 600 e $800 \mathrm{~m}$. À exceção das caatingas de sedimentos arenosos, já estudadas por Rodal (1983), os demais tipos vegetacionais são praticamente desconhecidos no estado de Pernambuco. Vale a pena salientar que a vegetação florestal perenifólia, os chamados "brejos", foram totalmente substituídos por plantações de capim e frutíferas. Este trabalho é o primeiro de uma série, cujo objetivo é caracterizar a organização comunitária dos diferentes tipos vegetacionais da chapada de São José no município de Buíque, Pernambuco.

\section{MATERIAL e MÉTODOS}

A área de estudo localiza-se na serra do Catimbau, uma das muitas de um conjunto que recebe, no município de Buíque, a denominação genérica de chapada de São José. Situa-se a 4 km da sede do município, na estrada que liga a sede ao distrito do Catimbau, na propriedade sítio $\mathrm{Ci}$ gano, em torno das coordenadas $8^{\circ} 67^{\prime} \mathrm{LS}$ e $37^{\circ} 11^{\prime}$ LW e altitude de $800 \mathrm{~m}$ (Fig. 1).

O posto meteorológico mais próximo da área localiza-se na sede do município e registra temperatura e precipitação médias anuais de $25^{\circ} \mathrm{C}$ e $1.095,9 \mathrm{~mm}$, respectivamente, com maior pluviosidade entre os meses de abril a junho (SUDENE, 1990). 


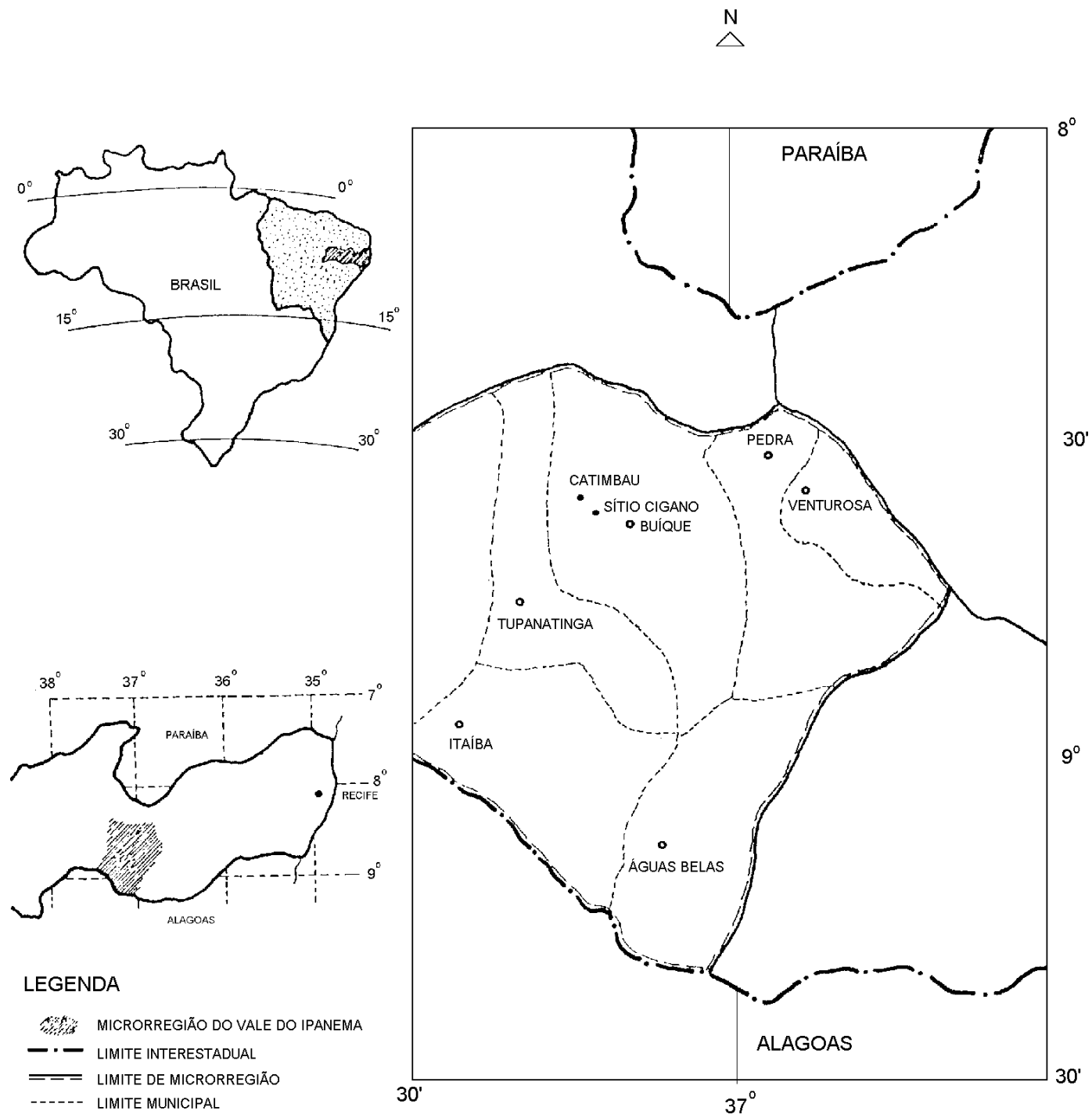

Fonte: CONDEPE (1993).

Fig. 1 - Localização do refúgio vegetacional do sítio Cigano, município de Buíque, Pernambuco.

$\mathrm{O}$ conjunto de serras pertence à formação Tacaratu, que no município de Buíque toma o aspecto de morros isolados ou serras com relevo forte ondulado e montanhoso. Exibe elevações em forma de mesetas, encostas íngremes e topos aplainados, tendo na sua base um relevo suave ondulado e vales abertos (Jacomine et al., 1973). Trata-se de uma formação datada do Siluriano e pertencente à bacia sedimentar do Jatobá. É formada por camadas basais de seqüência sedimentar, repousando discordantemente sobre o embasamento cristalino, formando arenitos de granulação predominantemente grosseira, micáceos ou mes- mo feldspáticos, evoluindo muitas vezes para conglomerados (Jacomine et al., 1973).

De maio de 1994 a abril de 1996, foram realizadas excursões mensais a diversas serras do município de Buíque, utilizando mapa altimétrico na escala 1:100.000, com a finalidade de selecionar a área de estudo, coletar material botânico para adquirir um maior conhecimento da flora e vegetação do conjunto das serras e realizar o levantamento fitossociológico.

Foram instalados 100 pontos quadrantes distribuídos em 10 picadas paralelas, interdistantes $30 \mathrm{~m}$, com 10 pontos quadrantes cada uma, dis- 
tanciados $10 \mathrm{~m}$. Em cada ponto foram amostrados todos os indivíduos, vivos ou mortos, exceto cipós e bromeliáceas, com diâmetro do caule $\oplus 3 \mathrm{~cm}$ no nível do solo e altura total $\oplus 1 \mathrm{~m}$. No primeiro ponto quadrante foram coletados ramos de todos os indivíduos amostrados, férteis ou estéreis, manualmente, com tesoura de poda. A partir do segundo ponto, foram coletadas apenas as espécies ainda não amostradas, desconhecidas ou aquelas encontradas férteis, das quais só se havia coletado material vegetativo. Todas as amostras receberam número de coleta registrado em caderneta de campo, na qual era anotado o hábito, altura, nome vulgar e outras características julgadas relevantes. Posteriormente, todo o material foi incorporado à coleção do herbário Professor Vasconcelos Sobrinho, pertencente à Universidade Federal Rural de Pernambuco (UFRPE).

Em herbário, o material foi identificado até o nível de gênero ou espécie, a partir de chaves de identificação botânica e bibliografia especializada, como Martius \& Eichler (1840/1906), Barroso et al. (1978, 1984, 1986), Irwin \& Barneby (1978 e 1982) ou por comparação com o material depositado nos herbários PEUFR e Dárdano de Andrade-Lima (IPA), pertencente à Empresa Pernambucana de Pesquisa Agropecuária. Parte das identificações foi procedida por especialistas como G. Lewis (K), G. M. Barroso (RB), M. C. Mamede (STF) e N. Hind (K). A grafia e a autoria das espécies foram verificadas através de Brumitt \& Powell (1992) e Stafleu \& Cowan (1976/1988). O sistema de classificação de Cronquist (1981) foi adotado para este trabalho.

$\mathrm{Na}$ análise da organização comunitária (Martins, 1990), foram calculados parâmetros gerais como densidade total, área basal total, alturas e diâmetros médios e máximos e parâmetros de densidade, freqüência e dominância para espécie, a partir das fórmulas descritas por Rodal et al. (1992) e Martins (1993) e o índice de diversidade de Shannon (Magurran, 1988).

Nesses cálculos, foi utilizado o pacote FITOPAC, na versão 1.0, de autoria do Professor George John Shepherd do Departamento de Botânica da Universidade Estadual de Campinas (UNICAMP). Adotou-se a abordagem de sinúsias para a análise da estrutura de tamanho. Segundo Barkman (1978), sinúsias representam um conjunto de plantas ou espécies com a mesma forma de vida. A maior altura individual de cada espécie definiu sua forma de vida. Consideraram-se as espécies como nanofanerófitas quando têm até $2 \mathrm{~m}$ de altu$\mathrm{ra}$; microfanerófitas com alturas entre 2,1 e $8 \mathrm{~m}$; e mesofanerófitas com mais de $8 \mathrm{~m}$ (Barkman, 1978).

\section{RESULTADOS E DISCUSSÃO}

A vegetação selecionada apresenta alguns sinais de perturbação que se evidenciam pela presença do cajueiro (Anacardium ocidentale) e por alguns indícios de corte seletivo. A fisionomia é arbustiva, os indivíduos são perenifólios, há poucos elementos arbóreos e o estrato subarbustivo é denso. Destaca-se da caatinga que circunda o conjunto de serras de Buíque principalmente por seu aspecto perenifólio e pela ausência de elementos espinhosos, como cactáceas e bromeliáceas.

No levantamento fitossociológico foram amostradas 35 espécies distribuídas por 32 gêneros e 24 famílias (Tabela 1). Além dessas espécies, outras 10, não amostradas, também atenderam ao critério de inclusão (Dasyphyllum sprengelianum var. inerme, Hymenaea courbaril L., Senna splendida var. gloriosa, Hirtella racemosa, Clusia nemorosa, Erythroxylum nummularia, Eugenia personii, Coutarea hexandra, Simarouba amara e Helicteres cf. velutina).

Ao serem levantados os 50 primeiros pontos quadrantes, 32 espécies já haviam sido amostradas. Com a duplicação do esforço de amostragem (100 pontos), houve a inclusão de apenas três espécies, Simaba cuneata, Lippia rigida e Turnera diffusa, todas com poucos indivíduos.

Analisando a distribuição, em outras áreas do Nordeste, de algumas espécies do componente lenhoso, observa-se que elas parecem estar distribuídas principalmente em áreas de vegetação mais aberta, como pode ser constatado pelos exemplos a seguir.

Representantes do grupo das leguminosas, como Bocoa mollis, ocorrem em caatinga e cerrado; Chamaescrista ramosa, em restinga, dunas costeiras, caatinga e cerrado; Mimosa lewisii, em campo rupestre, cerrado, campo geral e dunas costeiras; Senna cana var. cana, em cerrado, caatinga arbustiva e campos gerais; Senna macranthera var. micans, em caatinga perturbada, cerrado, campo geral e capoeiras de mata de cipó e Senna splendida var. gloriosa, em caatinga e campo geral (Lewis, 1987). 


\section{TABELA 1}

Famílias e espécies registradas no refúgio vegetacional do sítio Cigano, município de Buíque, Pernambuco, com o respectivo nome e número de coletor e forma de vida. NA - nanofanerófitas; MI - microfanerófitas.

\begin{tabular}{|c|c|c|}
\hline $\begin{array}{l}\text { Família/ } \\
\text { Espécie }\end{array}$ & $\begin{array}{l}\text { Nome e número } \\
\text { do coletor }\end{array}$ & $\begin{array}{l}\text { Forma } \\
\text { de vida }\end{array}$ \\
\hline $\begin{array}{l}\text { ANACARDIACEAE } \\
\text { Anacardium occidentale L. }\end{array}$ & E. Freire 3 & MI \\
\hline $\begin{array}{l}\text { ANNONACEAE } \\
\text { Rollinia leptopetala (R. E. Fries) Safford }\end{array}$ & A. Laurênio 363 & NA \\
\hline $\begin{array}{l}\text { ASTERACEAE } \\
\text { Gochnatia oligocephala (Gardner) Cabrera } \\
\text { Eremanthus capitatus (Spreng.) MacLeish } \\
\text { Dasyphyllum sprengelianum var. inerme (Gardner) Cabrera }\end{array}$ & $\begin{array}{l}\text { E. Freire } 20 \\
\text { K. Andrade } 139 \\
\text { M.J.N. Rodal } 290\end{array}$ & $\begin{array}{l}\text { MI } \\
\text { MI } \\
\text { MI }\end{array}$ \\
\hline $\begin{array}{l}\text { BIGNONIACEAE } \\
\text { Jacaranda rugosa A. Gentry }\end{array}$ & M.J.N. Rodal 429 & MI \\
\hline $\begin{array}{l}\text { CAESALPINIACEAE } \\
\text { Bauhinia acuruana Moric. } \\
\text { Caesalpinia microphylla Mart. ex Tul. } \\
\text { Chamaescrista ramosa (Vogel) H. S.Irwin \& Barneby } \\
\text { Hymenaea courbaril L. } \\
\text { Senna cana (Ness) H. S. Irwin \& Barneby var. cana } \\
\text { Senna macranthera var. micans (Ness) H.S. Irwin \& Barneby } \\
\text { Senna splendida var. gloriosa H.S. Irwin \& Barneby }\end{array}$ & $\begin{array}{l}\text { M. Tschá } 630 \\
\text { K. Andrade } 144 \\
\text { K. Andrade } 169 \\
\text { M.J. Hora } 42 \\
\text { A.P.S.Gomes } 96 \\
\text { M.J.N. Rodal } 522 \\
\text { K. Andrade } 45\end{array}$ & $\begin{array}{l}\text { NA } \\
\text { MI } \\
\text { MI } \\
\text { MI } \\
\text { MI } \\
\text { MI } \\
\text { MI }\end{array}$ \\
\hline $\begin{array}{l}\text { CELASTRACEAE } \\
\text { Maytenus imbricata Reiss. }\end{array}$ & K. Andrade 224 & MI \\
\hline $\begin{array}{l}\text { CHRYSOBALANACEAE } \\
\text { Hirtella ciliata Mart. \& Zucc. } \\
\text { Hirtella racemosa var, hexandra Will ex R. S. }\end{array}$ & $\begin{array}{l}\text { E. Freire } 18 \\
\text { K. Andrade } 250\end{array}$ & $\begin{array}{l}\text { MI } \\
\text { NA }\end{array}$ \\
\hline $\begin{array}{l}\text { CLUSIACEAE } \\
\text { Clusia nemorosa } \text { G. Mey }\end{array}$ & M.J.N. Rodal 277 & MI \\
\hline $\begin{array}{l}\text { COMBRETACEAE } \\
\text { Buchenavia capitata Eichl. }\end{array}$ & K. Andrade 217 & MI \\
\hline $\begin{array}{l}\text { ERYTHROXYLACEAE } \\
\text { Erythroxylum catingae Plowman } \\
\text { Erythroxylum nummularia Peyr. } \\
\text { Erythroxylum revolutum Mart. }\end{array}$ & $\begin{array}{l}\text { E. Freire } 19 \\
\text { L. Figueiredo } 329\end{array}$ & MI \\
\hline $\begin{array}{l}\text { FABACEAE } \\
\text { Bocoa mollis (Benth.) R. S. Cowan }\end{array}$ & M. Tschá 630 & MI \\
\hline $\begin{array}{l}\text { LAMIACEAE } \\
\text { Hyptis martiusii Benth. }\end{array}$ & K. Andrade 36 & NA \\
\hline $\begin{array}{l}\text { LAURACEAE } \\
\text { Ocotea } \text { cf. xanthocalix (Ness) Mez }\end{array}$ & L.Figueiredo 39 & MI \\
\hline $\begin{array}{l}\text { LYTHRACEAE } \\
\text { Lafoensia glyptocarpa Koehne }\end{array}$ & K. Andrade 110 & MI \\
\hline $\begin{array}{l}\text { MALPIGHIACEAE } \\
\text { Byrsonima vacciniifolia A. Juss. }\end{array}$ & A.Laurênio 324 & NA \\
\hline $\begin{array}{l}\text { MIMOSACEAE } \\
\text { Mimosa lewisii Barneby }\end{array}$ & K. Andrade 90 & MI \\
\hline Piptadenia obliqua (pers.) J. F. Macbr & K. Andrade 314 & MI \\
\hline $\begin{array}{l}\text { MYRTACEAE } \\
\text { Campomanesia aromatica (Aubl.) Grisebach } \\
\text { Eugenia personii McVaugh }\end{array}$ & $\begin{array}{l}\text { M. Tschá } 627 \\
\text { K. Andrade } 210\end{array}$ & $\begin{array}{l}\text { MI } \\
\text { MI }\end{array}$ \\
\hline
\end{tabular}


TABELA 1 (continuação)

\begin{tabular}{|c|c|c|}
\hline $\begin{array}{l}\text { Família/ } \\
\text { Espécie }\end{array}$ & $\begin{array}{l}\text { Nome e número } \\
\text { do coletor }\end{array}$ & $\begin{array}{r}\text { Forma } \\
\text { de vida }\end{array}$ \\
\hline \multicolumn{3}{|l|}{ MYRTACEAE (cont.) } \\
\hline Eugenia pseudopsidium Jacquin & K. Andrade 133 & MI \\
\hline Eugenia punicifolia Humb., Bonpl. \& Kunth & M.J.N. Rodal 520 & MI \\
\hline Myrcia multiflora (Lam.) DC & M.J.N. Rodal 526 & MI \\
\hline Myrcia myrsinoides Berg. & A. Laurênio 527 & NA \\
\hline \multicolumn{3}{|l|}{ NYCTAGINACEAE } \\
\hline Guapira $\mathrm{sp}$ & A.Laurênio 327 & MI \\
\hline \multicolumn{3}{|l|}{ OCHNACEAE } \\
\hline Ouratea blanchetiana Engl. & K. Andrade 231 & NA \\
\hline \multicolumn{3}{|l|}{ OLACACEAE } \\
\hline Schoepfia brasiliensis A. DC. & K. Andrade 222 & MI \\
\hline \multicolumn{3}{|l|}{ RUBIACEAE } \\
\hline Coutarea hexandra K. Schum. & K. Andrade 93 & MI \\
\hline \multicolumn{3}{|l|}{ RUTACEAE } \\
\hline Zanthoxylum stelligerum Turcz. & K. Andrade 53 & NA \\
\hline \multicolumn{3}{|l|}{ SAPOTACEAE } \\
\hline Manilkara rufula Miq. & K. Andrade 310 & MI \\
\hline \multicolumn{3}{|l|}{ SIMAROUBACEAE } \\
\hline Simaba cuneata A.St.-Hil. \& Tul. & M.J. Campelo 18 & MI \\
\hline Simarouba amara Aubl. & K. Andrade 227 & MI \\
\hline \multicolumn{3}{|l|}{ STERCULIACEAE } \\
\hline Helicteres velutina $\mathrm{K}$. Schum. & M.J.N. Rodal 466 & MI \\
\hline \multicolumn{3}{|l|}{ TURNERACEAE } \\
\hline Turnera diffusa Willd. & E.Freire 49 & NA \\
\hline \multicolumn{3}{|l|}{ VERBENACEAE } \\
\hline Lippia rigida Schauer & M.J.N.Rodal 289 & MI \\
\hline
\end{tabular}

Elementos de outras famílias, como Hirtella ciliata (Chrysobalanaceae), ocorrem em cerrado de altitude (Stannard, 1995); Lippia rigida (Verbenaceae), em campo rupestre (Atkins, 1995); Dasyphyllum sprengelianum var. inerme (Asteraceae), em cerrado (Hind, 1995). Outras, como Eugenia punicifolia (Myrtaceae), ocorrem em campo rupestre, cerrado de altitude e carrasco (Lughadha, 1995; Araújo et al., prelo); Campomanesia aromatica (Myrtaceae) e Zanthoxylum stelligerum ( Rutaceae), em áreas de carrasco (Araújo et al., prelo); e Helicteres cf. velutina (Sterculiaceae), em áreas de caatinga sobre sedimentos arenosos (Rodal, 1983).

Além do conjunto de espécies acima citadas, mais relacionadas a vegetações mais abertas, existe um outro formado por espécies distribuídas preferencialmente em vegetação florestal, como as caatingas arbóreas e florestas secas ou matas úmi- das. Exemplos seriam Buchenavia capitata (Combretaceae) e Simaba cuneata (Simaroubaceae), presentes em floresta úmida (Andrade-Lima, 1954), Manilkara rufula (Sapotaceae), em floresta subúmida e de galeria (Pennington, 1990), e Schoepfia brasiliensis (Olacaceae), em floresta de galeria, caatinga e restinga (Sleumer, 1984).

Os 400 indivíduos arbustivos e arbóreos amostrados ocuparam uma área de aproximadamente 0,18 ha, correspondendo a uma densidade total de $2.208 \mathrm{ind}$./ha, área basal de $6,07 \mathrm{~m}^{2} / \mathrm{ha}$, alturas e diâmetros médios e máximos de 2,3 e $7 \mathrm{~m}$ e 5,1 e $22 \mathrm{~cm}$, respectivamente, e maiores concentrações de altura e diâmetro entre as classes de 1 a $2 \mathrm{~m}$ de altura e 3 a $6 \mathrm{~cm}$ de diâmetro (Tabela 2).

Na Tabela 2, é possível observar que o valor da densidade total da área de estudo foi inferior aos registrados para a transição caatinga-carrasco estudada por Oliveira et al. (1997), para as áreas de 
TABELA 2

Parâmetros fitossociológicos registrados no refúgio vegetacional do sítio Cigano, município de Buíque, Pernambuco, e em levantamentos de caatinga e carrasco. *Classes com maior número de indivíduos.

\begin{tabular}{|c|c|c|c|c|c|c|c|c|}
\hline Parâmetros & $\begin{array}{c}\text { Densidade } \\
\text { total } \\
\text { (ind./ha) }\end{array}$ & $\begin{array}{c}\text { Área basal } \\
\text { total } \\
\left(\mathrm{m}^{2} / \mathbf{h a}\right)\end{array}$ & $\begin{array}{c}\text { Altura } \\
\text { média } \\
\text { (m) }\end{array}$ & $\begin{array}{c}\text { Altura } \\
\text { máxima } \\
\text { (m) }\end{array}$ & $\begin{array}{l}\text { Diâmetro } \\
\text { médio } \\
(\mathrm{cm})\end{array}$ & $\begin{array}{c}\text { Diâmetro } \\
\text { máximo } \\
(\mathrm{cm})\end{array}$ & $\begin{array}{c}\text { Classes } \\
\text { de altura* } \\
\text { (m) }\end{array}$ & $\begin{array}{c}\text { Classes } \\
\text { de diâmetro } \\
(\mathrm{cm})\end{array}$ \\
\hline $\begin{array}{l}\text { Sítio Cigano } \\
\text { (este trabalho) }\end{array}$ & 2.208 & 6,07 & 2,30 & 7,0 & 5,10 & 22,0 & $1-2$ & $3-6$ \\
\hline $\begin{array}{l}\text { Caruaru (Alcoforado } \\
\text { Filho, 1993) }\end{array}$ & 3.210 & 24,90 & 4,70 & 19,0 & 7,20 & 47,0 & $2-8$ & $3-6$ \\
\hline $\begin{array}{l}\text { Padre Marcos } \\
\text { (Oliveira et al., 1997) }\end{array}$ & 4.618 & 24,20 & 3,20 & 9,0 & 8,08 & 48,0 & $1-2$ & $3-6$ \\
\hline $\begin{array}{l}\text { Fasa } \\
\text { (Rodal, 1992) }\end{array}$ & 1.810 & 15,84 & 3,73 & 10,5 & 8,09 & 48,0 & $1-2$ & $3-6$ \\
\hline $\begin{array}{l}\text { Poço do Ferro } \\
\text { (Rodal, 1992) }\end{array}$ & 2.172 & 15,61 & 3,37 & 13,0 & 7,89 & 44,0 & $2-3$ & $3-6$ \\
\hline $\begin{array}{l}\text { Baixa Fria } \\
\text { (Araújo et al., 1998) }\end{array}$ & 5.952 & 14,20 & 3,80 & 8,5 & 5,00 & 29,0 & $3-5$ & $3-6$ \\
\hline $\begin{array}{l}\text { Carrasco } \\
\text { (Araújo et al., 1998) }\end{array}$ & 5.722 & 26,80 & 5,40 & 13,0 & 6,50 & 39,6 & 4-5 & $3-6$ \\
\hline $\begin{array}{l}\text { Estrondo } \\
\text { (Araújo et al., 1998) }\end{array}$ & 6.596 & 19,50 & 5,30 & 11,0 & 5,40 & 27,0 & $4-5$ & $3-6$ \\
\hline
\end{tabular}

carrasco levantadas por Araújo et al. (1998) e para a caatinga arbórea analisada por Alcoforado Filho (1993), semelhante à da caatinga arbustivo-arbórea de Poço do Ferro analisada por Rodal (1992) e superior ao da caatinga arbustivo-arbórea da Fasa estudada por Rodal (1992).

$\mathrm{O}$ valor da área basal total foi inferior aos registrados para a transição caatinga-carrasco estudada por Oliveira et al. (1997), para as duas caatingas arbustivo-arbóreas levantadas por Rodal (1992), para as áreas de carrasco avaliadas por Araújo et al. (1998) e para a caatinga arbórea analisada por Alcoforado Filho (1993). Como os dados revelam, trata-se de um parâmetro que individualiza a vegetação da área de estudo dos demais levantamentos analisados (Tabela 2).

Em termos de classes de altura, apenas este trabalho, a transição caatinga-carrasco de Padre Marcos (Oliveira et al., 1997) e a caatinga arbustivo-arbórea de Fasa (Rodal, 1992) tiveram maior concentração de indivíduos entre a classe de 1 a $2 \mathrm{~m}$, ficando os demais com intervalos superiores. Já com relação às classes de diâmetro, todos os levantamentos tiveram maior número de indivíduos, na classe de 3 a $6 \mathrm{~cm}$, variando apenas na proporção do número de indivíduos, que oscilou de $44 \%$ na caatinga arbustivo-arbórea de Fasa (Rodal, 1992) a $72 \%$ no carrasco de Estrondo (Araújo et al., 1998).
Dos 8 levantamentos analisados na Tabela 2, a vegetação do sítio Cigano distingue-se das caatingas e dos carrascos analisados pelas suas menores alturas (médias e máximas). Em termos de diâmetro, todavia, a área de estudo apresentou valores próximos a algumas das áreas de carrasco estudadas por Araújo et al. (1998), individualizando-se destas pelas menores alturas.

Dos parâmetros acima discutidos, pode-se considerar que a área de estudo apresenta uma fisionomia arbustiva distinta dos padrões encontrados nos levantamentos de carrasco ou de caatinga, seja arbustiva-arbórea ou arbórea, já realizados no Nordeste.

Deve-se salientar a ausência de levantamentos quantitativos em caatingas com padrão fisionômico arbustivo como o da área de estudo. De qualquer forma, continuaria a haver a separação por conta da caducifolia dos elementos da caatinga.

No nível estrutural, a organização das espécies pelos seus valores de IVI (Tabela 3 ), exceto pela espécie mais importante, Eremanthus capitatus, seguiu principalmente a densidade e freqüência relativas, comportamento semelhante ao encontrado nas caatingas arbustivo-arbóreas (Rodal, 1992) e arbórea (Alcoforado Filho, 1993), no carrasco (Araújo et al., 1998) e na transição caatinga-carrasco (Oliveira et al., 1997). 
TABELA 3

Espécies amostradas no refúgio vegetacional do sítio Cigano, município de Buíque, Pernambuco, e seus parâmetros fitossociológicos, em ordem decrescente pelo índice do valor de importância por espécie (IVI).

\begin{tabular}{|c|c|c|c|c|c|}
\hline Família/Espécie & $\begin{array}{l}\text { № } \\
\text { ind }\end{array}$ & $\begin{array}{l}\text { DR } \\
(\%)\end{array}$ & $\begin{array}{l}\text { FR } \\
(\%)\end{array}$ & $\begin{array}{l}\text { DoR } \\
(\%)\end{array}$ & IVI \\
\hline Eremanthus capitatus & 59 & 14,75 & 13,58 & 24,53 & 52,86 \\
\hline Piptadenia obliqua & 65 & 16,25 & 14,51 & 10,83 & 41,59 \\
\hline MORTO & 57 & 14,25 & 12,65 & 9,20 & 36,10 \\
\hline Gochnatia oligocephala & 33 & 8,25 & 7,72 & 13,68 & 29,65 \\
\hline Senna cana var. cana & 42 & 10,50 & 9,88 & 6,27 & 26,65 \\
\hline Eugenia punicifolia & 31 & 7,75 & 8,33 & 3,40 & 19,48 \\
\hline Anacardium occidentale & 9 & 2,25 & 2,78 & 7,22 & 12,25 \\
\hline Guapira sp & 18 & 4,50 & 5,25 & 2,19 & 11,94 \\
\hline Lafoensia gliptocarpa & 8 & 2,00 & 2,47 & 5,34 & 9,81 \\
\hline Hirtella ciliata & 8 & 2.00 & 2,16 & 4,51 & 8,67 \\
\hline Zanthoxylum stelligerum & 10 & 2,50 & 2,47 & 1,49 & 6,46 \\
\hline Buchenavia capitata & 5 & 1,25 & 1,54 & 1,52 & 4,31 \\
\hline Manilkara rufula & 3 & 0,75 & 0,62 & 2,44 & 3,81 \\
\hline Erythroxylum revolutum & 5 & 1,25 & 1,54 & 0,63 & 3,42 \\
\hline Chamaescrista ramosa & 5 & 1,25 & 1,54 & 0,45 & 3,24 \\
\hline Erythroxylum catingae & 5 & 1,25 & 1,23 & 0,56 & 3,04 \\
\hline Simaba cuneata & 3 & 0,75 & 0,62 & 1,40 & 2,77 \\
\hline Campomanesia aromatica & 4 & 1.00 & 1,23 & 0,38 & 2,61 \\
\hline Mimosa lewisii & 3 & 0,75 & 0,93 & 0,33 & 2,42 \\
\hline Senna macranthera var. micans & 3 & 0,75 & 0,93 & 0,33 & 2,01 \\
\hline Myrcia multiflora & 3 & 0,75 & 0,93 & 0,28 & 1,96 \\
\hline Eugenia pseudopsidium & 3 & 0,75 & 0,93 & 0,21 & 1,89 \\
\hline Caesalpinia microphylla & 3 & 0.75 & 0,93 & 0,74 & 1,67 \\
\hline Schoepfia brasiliensis & 2 & 0,50 & 0,62 & 0,34 & 1,46 \\
\hline Lippia rigida & 2 & 0,50 & 0,62 & 0,15 & 1,27 \\
\hline Rollinia leptopetala & 1 & 0,25 & 0,31 & 0,65 & 1,21 \\
\hline Ouratea blanchetiana & 1 & 0,25 & 0,31 & 0,45 & 1,01 \\
\hline Ocotea xanthocalyx & 1 & 0,25 & 0,31 & 0,32 & 0,88 \\
\hline Maytenus imbricata & 1 & 0,25 & 0,31 & 0,23 & 0,79 \\
\hline Bocoa mollis & 1 & 0,25 & 0,31 & 0,09 & 0,65 \\
\hline Bauhinia acuruana & 1 & 0,25 & 0,31 & 0,09 & 0,65 \\
\hline Jacaranda rugosa & 1 & 0,25 & 0,31 & 0,08 & 0,64 \\
\hline Pisidium myrsinoides & 1 & 0,25 & 0,31 & 0,08 & 0,64 \\
\hline Hyptis martiusii & 1 & 0,25 & 0,31 & 0,07 & 0,63 \\
\hline Turnera diffusa & 1 & 0,25 & 0,31 & 0,07 & 0,63 \\
\hline Byrsonima vacciniifolia & 1 & 0,25 & 0,31 & 0,07 & 0,63 \\
\hline
\end{tabular}

№ ind. - número de indivíduos; DoR - dominância relativa; FR - freqüência relativa; DR densidade relativa.

Considerando as sinúsias florísticas, foram encontradas 8 nanofanerófitas, 28 microfanerófitas e nenhuma mesofanerófita. Comparando esses resultados com levantamentos em áreas de caatinga (arbórea ou arbustivo-arbórea) e de carrasco, podese observar que a área de estudo foi a única a não apresentar mesofanerófitas (Tabela 4).

Esses resultados corroboram os dados já discutidos, confirmando o padrão fisionômico arbus- tivo da área, distinto das caatingas e carrascos analisados.

Essas diferenças provavelmente estão relacionadas ao tipo de solo e relevo em que aquelas formações vegetacionais ocorrem.

Diferenças fisionômicas em formações vegetacionais secas e sazonais também foram apontadas por Murphy \& Lugo (1995) ao analisarem os parâmetros vegetacionais de 11 levantamen- 
TABELA 4

Comparação do número de espécies por sinúsia no refúgio vegetacional do sítio Cigano, município de Buíque, Pernambuco e em outros levantamentos em caatinga e carrasco.

B. V. - Boa Vista; NANO - sinúsia nanofanerofitica; MICRO - sinúsia microfanerofítica; MESO - sinúsia mesofanerofitica.

\begin{tabular}{lcccc}
\hline & \multicolumn{3}{c}{ SINÚSIA } & \\
\cline { 2 - 4 } MUNICÍPIO ou ÁREA /AUTOR & NANO & MICRO & MESO & TOTAL \\
\hline Sítio Cigano (este trabalho) & 08 & 28 & - & 36 \\
Serra Talhada - 500 m (Ferraz 1994) & - & 27 & 08 & 35 \\
Serra Talhada - 700 m (Ferraz 1994) & - & 18 & 04 & 22 \\
Caruaru (Alcoforado Filho 1993) & 08 & 38 & 19 & 65 \\
Padre Marcos (Oliveira et al. 1997) & 04 & 33 & 02 & 39 \\
Fasa (Rodal 1992) & 01 & 19 & 04 & 24 \\
B. V. margem esquerda (Rodal 1992) & 01 & 08 & 13 & 22 \\
B. V. margem direita (Rodal 1992) & 01 & 11 & 16 & 28 \\
\hline
\end{tabular}

tos na América Central e Caribe. Os autores mostram que, sob os mesmos totais pluviométricos, é possível encontrar florestas semidecíduais com alturas bastante distintas em função de variações topográficas e pedológicas.

O índice de diversidade de Shannon para espécie, 2,73 nats/ind., foi inferior aos registrados para Baixa Fria e Estrondo (Araújo et al., 1998), cujos valores foram 3,03 e 2,91 nats/ind., e superior ao citado para a área Carrasco (Araújo et al., 1998), a transição caatinga-carrasco (Oliveira et al., 1997), as duas caatingas arbustivo-arbóreas (Rodal, 1992) e para a caatinga arbórea (Alcoforado Filho, 1993), cujos valores foram 2,57, 2,65, 2,54, 2,25 e 3,09 nats/ind., respectivamente.

\section{CONCLUSÕES}

A área de estudo apresenta uma fisionomia arbustiva, perenifólia, formada por nano e microfanerófitas e com baixa área basal, nitidamente distinta das caatingas e dos carrascos nordestinos já estudados. Parte dos representantes de sua flora apresenta distribuição geográfica abrangendo formações vegetais abertas, como campos rupestres, cerrados e outros.

\section{REFERÊNCIAS BIBLIOGRÁFICAS}

ALCOFORADO-FILHO, F. G., 1993, Composição florística e fitossociologia de uma área de caatinga arbórea no município de Caruaru, PE. Dissertação de Mestrado em Botânica, UFRPE, Recife, 220p.
ANDRADE-LIMA, D. de, 1954, Contribution to the study of the flora of Pernambuco, Brazil. Recife, Universidade Federal Rural de Pernambuco, 154p. (Monografia 1).

ARAÚJO, E. L., SAMPAIO, E. V. S. B. \& RODAL, M. J. N., 1995, Composição florística e fitossociológica de três áreas de caatinga. Revista Brasileira de Biologia, 55(4): 595-607.

ARAÚJO, F. S., SAMPAIO, E. V. S. B., RODAL, M. J. N. \& FIGUEIREDO, M. A., 1998, Organização comunitária do componente lenhoso de três áreas de carrasco em Nova Oriente, CE. Revista Brasileira de Biologia, 58(1): 85-95.

ARAÚJO, F. S., SAMPAIO, E. V. S. B., FIGUEIREDO, M. A., RODAL, M. J. N. \& FERNANDES, A. G., prelo, Composição florística da vegetação de carrasco, Novo Oriente, CE. Revista Brasileira de Botânica.

ATKINS, S., 1995, Verbenaceae, pp. 621-630. In: B.L. Stannard (ed), Flora of the Pico das Almas, Royal Botanic Gardens, Kew, London, 852p.

BARKMAN, J. J., 1978, Synusial approaches to classification, pp. 111-116. In: R. H. Whittaker (ed), Classification of plant communities, 270p, W. Junk, The Hague.

BARROSO, G. M., GUIMARÃES, E. F., ICHASO, C. L. F., COSTA, C. G. \& PEIXOTO, A. L, 1978, Sistemática de angiospermas do Brasil. Livros Técnicos e Científicos, EDUSP, São Paulo, 1ํ vol., 255p.

Barroso, G. M., PeiXoto, A. L., COStA, C. G., ICHASO, C. L. F. \& GUIMARÃES, E. F., 1984, Sistemática de angiospermas do Brasil. Universidade Federal de Viçosa, Imprensa Universitária, Viçosa, $2^{\circ}$ vol., 377p.

BArroso, G. M., PEIXoto, A. L., COSTA, C. G., ICHASO, C. L. F. \& GUIMARÃES, E. F., 1986, Sistemática de angiospermas do Brasil. Universidade Federal de Viçosa, Imprensa Universitária, Viçosa, 3o vol., 326p.

BRUMMITT, R. F. \& POWELL, C. E., 1992, Authors of plant names. Royal Botanic Gardens Kew, London, 732p. 
CRONQUIST, A., 1981, An integrated system of classification of flowering plants. Columbia University Press, New York, 1262p.

FERNANDES, A., 1996, Fitogeografia do semi-árido. Anais da 4a Reunião Especial da Sociedade Brasileira para o Progresso da Ciência, SBPC, Feira de Santana, pp. 215219.

FERRAZ, E. M. N., 1994, Variação florístico-vegetacional na região do vale do Pajeú, Pernambuco. Dissertação de Mestrado em Botânica, UFRPE, Recife, 197p.

FERRAZ, E. M. N., RODAL, M. J. N., SAMPAIO, E. V. S. B. \& PEREIRA, R. de C. A., 1998, Composição florística em trechos de vegetação de caatinga e brejo de altitude na região do Vale do Pajeú, Pernambuco. Revista. Brasileira de Botânica, 21(1): 7-15.

HIND, D. J. N, 1995, Compositae, pp.175-278. In: B. L. Stannard (ed), Flora of the Pico das Almas, Royal Botanic Gardens, Kew, London 852p.

IBGE/Departamento de Recursos Naturais e Estudos Ambientais, 1992, Manual técnico da vegetação brasileira. Rio de Janeiro, 92p. (Manuais Técnicos de Geociências, 1.)

INSTITUTO DE PLANEJAMENTO DE PERNAMBUCO CONDEPE, 1993, Perfil sócio-demográfico de Pernambuco, Recife (material utilizado: mapa das microrregiões de Pernambuco).

IRWIN, H. S. \& BARNEBY, R. C., 1978, Monographic Studies in Cassia (Leguminosae Caesalpinioideae) III. Sections Absus and Grimaldia. Memories of the New York Botanical Garden, 30: 1-269.

IRWIN, H. S. \& BARNEBY, R. C., 1982, The American Cassiinae - A synoptical revision of leguminosae subtribe in the New world. Memories of the New York Botanical Garden, 35(1-2): 1-918.

JACOMINE, P. T., CAVALCANTI, A. C., BURGOS, N., PESSOA, S. C. P. \& SILVEIRA, C. O., 1973, Levantamento exploratório-reconhecimento de solos do estado de Pernambuco. SUDENE/Divisão de Pesquisa Pedológica, Recife, v. 1, (Boletim Técnico 26, Pedologia 14.), $175 \mathrm{p}$.

LEWIS, G. P., 1987, Legumes of Bahia. Royal Botanic Gardens, Kew, London. 369p.

LUGHADHA, E. N., 1995, Myrtaceae, pp. 492-517. In: B L. Stannard (ed), Flora of the Pico das Almas, Royal Botanic Gardens, Kew, London, 852p.

LYRA, A. L. R. T., 1982, Efeito do relevo na vegetação de duas áreas do município do Brejo da Madre de Deus $(P E)$. Dissertação de Mestrado em Botânica, UFRPE, Recife, 106p.

MAGURRAN, A. E., 1988, Ecological diversity and its measurement. Princeton University, New Jersey, 197p.

MARTINS, F. R., 1990, Atributos de comunidades vegetais. Quid, 9(1-2 ): 13-17.

MARTINS, F. R., 1993, A estrutura de uma floresta mesófila. $2^{\mathrm{a}}$ ed., UNICAMP, Campinas, 246p.
MARTIUS, C. F. P. von \& EICHLER, A. G., 1840/1906, Flora Brasiliensis: enumeratio plantarum in Brasilia hactenus detectarum. Monachii. Lipsiae. Reimpressão 1965, Verlag von J. Cramer, 15 vols.

MAYO, S. J. \& FEVEREIRO, V. P. B., 1982, Mata de PauFerro - A pilot study of the Brejo Forest of Paraiba, Brazil. Bentham - Moxon Trust, Royal Botanic Gardens, Kew, London. 29p.

MURPHY, P. G. \& LUGO, A. E., 1995, Dry forest of Central America and the Caribbean, pp. 9-34. In: S. H. Bullock, H. A. Mooney \& E. Medina (eds.), Seasonal Dry Tropical forests, Cambridge University Press, Cambridge, 450p.

OLIVEIRA, M. E. A., SAMPAIO, E. V. S. B., CASTRO, A. A. J. de F. \& RODAL, M. J. N., 1997, Flora e fitossociologia de uma área de transição carrasco-caatinga de areia em Padre Marcos, Piauí. Naturalia. São Paulo, 22: 131-150.

PENNINGTON, T. D., 1990, Flora neotropica: Sapotaceae. New York, Organization for Flora Neotropica by Hafner Publishing Company, 770p. (Monograph, 52.)

RODAL, M. J. N., 1983, Fitoecologia de uma área do médio vale do Moxotó, Pernambuco. Dissertação de Mestrado em Botânica, UFRPE, Recife, 132p.

RODAL, M. J. N., 1992, Fitossociologia da vegetação arbustivo-arbórea em quatro áreas de caatinga em Pernambuco. Tese de Doutorado em Biologia Vegetal, UNICAMP, Campinas, 224p.

RODAL, M. J. N., SAMPAIO, E. V. S. B. e FIGUEIREDO, M. A., 1992, Manual sobre métodos de estudo florístico e fitossociológico - ecossistema caatinga. Sociedade Botânica do Brasil, Brasília, 24p.

SANTOS, M. F. A. V., 1987, Características de solo e vegetação em sete áreas de Parnamirim, Pernambuco. Dissertação de Mestrado em Botânica, UFRPE, Recife, 230p.

SILVA, I. H., 1991, Correlações entre a vegetação e tipos distintos de solos do baixio de Irecê, Bahia. Dissertação de Mestrado em Botânica. UFRPE, Recife, 104p.

SLEUMER, B., 1984, Flora neotropica: Olacaceae. New York, Organization for Flora Neotropica by Hafner Publishing Company, 157 p. (Monograph, 35.)

SOUZA, G. V., 1983, Estrutura da vegetação da caatinga hipoxerófila do estado de Sergipe. Dissertação de Mestrado em Botânica, UFRPE, Recife, 95p.

STAFLEU, F. A. \& COWAN, R. S., 1976/1988, Taxonomic Literature. Scheltema \& Holkema, Utrecht, 7 vols.

STANNARD, B. L., 1995, Chrysobalanaceae, pp. 173-174. In: B. L. Stannard (ed), Flora of the Pico das Almas, Royal Botanic Gardens, Kew, London, 852p.

SUDENE, 1990, Dados pluviométricos mensais do Nordeste. Recife, Pernambuco. 